\title{
Elucidation of active oxygen sites upon delithiation
}

\section{of $\mathrm{Li}_{3} \mathrm{IrO}_{4}$}

Haifeng Li ${ }^{1}$, Arnaud J. Perez ${ }^{2,3}$, Beata Taudul ${ }^{4,7}$, Teak D. Boyko ${ }^{5}$, John W. Freeland ${ }^{6}$, MarieLiesse Doublet $^{4,7}$, Jean-Marie Tarascon ${ }^{2,3,7}$, Jordi Cabana ${ }^{1}$

${ }^{1}$ Department of Chemistry, University of Illinois at Chicago, Chicago, Illinois 60607, United States

${ }^{2}$ Collège de France, Chimie du Solide et de l'Energie, UMR 8260, 11 Place Marcelin Berthelot, 75231 Paris Cedex 05, France

${ }^{3}$ Sorbonne Université, 4 Place Jussieu, F-75005 Paris, France

${ }^{4}$ Institut Charles Gerhardt, Univ. Montpellier, CNRS, ENSCM, 34095 Montpellier, France

${ }^{5}$ Canadian Light Source, Saskatoon, Saskatchewan, S7N 2V3, Canada

${ }^{6}$ Advanced Photon Source, Argonne National Laboratory, Lemont, Illinois 60439, United States

${ }^{7}$ Réseau sur le Stockage Electrochimique de l'Energie (RS2E) CNRS FR3459, 33 rue Saint Leu, 80039 Amiens Cedex, France 


\begin{abstract}
Transformational increases in the storage capacity of battery cathodes could be achieved by tapping into the redox activity at oxide ligands in addition to conventional transition metal couples. Yet the key signatures that govern such lattice oxygen redox (LOR) have not been ascertained. $\mathrm{Li}_{3} \mathrm{IrO}_{4}$ has the largest reversible LOR, rendering it a unique model system. Here, Xray spectroscopy and computational simulations reveal that $\mathrm{LOR}$ in $\mathrm{Li}_{3} \mathrm{IrO}_{4}$ is selectively compensated via $\mathrm{O}$ sites with 3 lone pairs, which are activated by $\mathrm{Li} / \mathrm{Ir}$ disorder. The 2 -electron LOR can be reversed to regenerate the initial state without unlocking competing bulk reactions observed in many other compounds. We uncover an intricate interplay between stoichiometry, $\mathrm{O}$ coordination and non-bonding states in LOR and pinpoint spectroscopic signatures. This interplay is indispensable to design materials with $3 d$ metals that fulfill the promise of LOR to overcome the bottlenecks of current cathodes for future implementation in practical batteries.
\end{abstract}


The manipulation of the redox chemistry of the transition metal $(T M)$ - oxide bond in solids enabled the advent and dominance of Li-ion batteries as storage devices in the wireless revolution and as rapidly expanding alternative in transportation and the grid, ${ }^{1}$ propelling our push away from the fossil fuel paradigm. Ironically, the redox processes of layered $\mathrm{Li}[T M] \mathrm{O}_{2}$ $(T M=\mathrm{Co}, \mathrm{Ni}, \mathrm{Mn}$, among others) cathodes, concurrent with $\mathrm{Li}$ (de)intercalation, also determine the current roadblocks to transformational energy density that could lead them to rule these mass markets as well. ${ }^{2}$ Full delithiation cannot be achieved without severely compromising stability, ${ }^{3-6}$ because the covalent $T M-\mathrm{O}$ bond, conventionally labeled as the formal oxidation state of $T M$, becomes too oxidized. To disrupt the constraints of such "cationic redox" (CR, involving TM ndO $2 p$ mixed states), researchers have sought to tap into the redox activity of oxide anions. In particular, layered oxides with an over-stoichiometry of $\mathrm{Li}, \mathrm{Li}\left[\mathrm{Li}_{\mathrm{x}} T M_{1-\mathrm{x}}\right] \mathrm{O}_{2}$, have attracted considerable excitement because their capacities approach $300 \mathrm{mAhg}^{-1} .^{7-11}$ This vertical step in performance is proposed to stem from combining CR and participation of non-bonding states of O (termed as "lattice O redox", LOR). ${ }^{12,13}$ Despite their enhanced electrochemical activity, these cathode materials suffer from unacceptable energy efficiency and degradation. ${ }^{14-17}$ The most reversible cases involve heavy metals, such as $\operatorname{Ir}^{18-20}$ which are not economically viable for use in a battery.

It is imperative to achieve a holistic understanding of LOR to design materials containing base metals with high storage capacity that is efficient and reversible. In terms of electronic structure, a key descriptor is an $\mathrm{O} / T M$ ratio greater than $2,{ }^{21,22}$ which generates $\mathrm{O} 2 p$ states that are only connected to Li through electrostatic interactions, rendering them essentially nonbonding. Hong et al. proposed that additional active non-bonding states must be generated in $\mathrm{Li}_{2} T M \mathrm{O}_{3}\left(\mathrm{Li}\left[\mathrm{Li}_{1 / 3} T M_{2 / 3}\right] \mathrm{O}_{2}\right)$ by the creation of in-plane defects ${ }^{23}$ through out-of-plane cationic 
migration $^{24}$ Xie et al. further predicted that the greatest enhancement could be achieved in $\mathrm{Li}_{3} T M \mathrm{O}_{4}\left(\mathrm{Li}\left[\mathrm{Li}_{1 / 2} T M_{1 / 2}\right] \mathrm{O}_{2}\right){ }^{25}$ Indeed, the most striking activity was accomplished with $\mathrm{Li}_{3} \mathrm{IrO}_{4}$ ( $\mathrm{Li}\left[\mathrm{Li}_{1 / 2} \mathrm{Ir}_{1 / 2}\right] \mathrm{O}_{2}$ ), with reversible cycling of $2 \mathrm{~mol} \mathrm{Li}$ to form a very highly oxidized phase which does not fit conventional $\mathrm{CR},{ }^{19}$ the highest extent of LOR per mol TM of any known compound. Prior evidence indicates that no out-of-plane migration of Ir occurs ${ }^{19}$ because it faces a high barrier in a layered structure. ${ }^{24}$ Consequently, the reasons that make $\mathrm{Li}_{3} T M \mathrm{O}_{4}$ in general, and $\mathrm{Ir}$ in particular, so special remain to be elucidated. Since the number of holes per O site is critical to define reactivity, ${ }^{26}$ it is important to experimentally ascertain whether key $\mathrm{O}$ states underpin the unique ability of $\mathrm{Li}_{3} \mathrm{IrO}_{4}$ to undergo LOR.

Having established the redox inactivity of Ir earlier, ${ }^{19}$ here, we follow the changes of $\mathrm{O}$ in the highly oxidized states reached via deintercalation of $\mathrm{Li}_{3} \mathrm{IrO}_{4}$. A combination of X-ray spectroscopy (Figure 1) and computational modeling uncovered the existence of two nonequivalent $\mathrm{O}$ sites showing different involvement in the reaction, with a critical role of the site with 3 lone pairs. Reintercalation reproduces the initial electronic structure, contributing to low voltage hysteresis. $\mathrm{Li}_{3} \mathrm{IrO}_{4}$ reacts through LOR without producing the RIXS signatures commonly associated with it, ${ }^{23,24,27,28}$ suggesting that multiple possible pathways of LOR may exist. The findings solidify our understanding of unconventional, yet chemically reversible ligand reactivity transcending classical CR paths.

Electrochemistry and spectroscopy of the pristine state. $\mathrm{Li}_{3} \mathrm{IrO}_{4}$ can be oxidized to, nominally, $\mathrm{Li}_{1} \mathrm{IrO}_{4}$ through a long plateau at 3.9-4.0 $\mathrm{V} \mathrm{vs} \mathrm{Li}^{+} / \mathrm{Li}^{0}$ (Figure 1a), a process with high electrochemical reversibility. ${ }^{19}$ Further oxidation to $4.5 \mathrm{~V}$ induces amorphization to "a-IrO 3 ", an irreversible step inducing notable voltage hysteresis and capacity loss upon subsequent reduction. ${ }^{19}$ Perez et al. reported a minor shift of the Ir $_{\text {III- }}$ edge XAS to high energy in the initial 
stages of deintercalation, with the position staying largely constant thereafter, ${ }^{19}$ indicating the involvement of $\mathrm{O}$ in the charge compensation. To evaluate this hypothesis, electrodes were harvested at representative states (Figure 1a).

The O K-edge X-ray absorption spectroscopy (XAS) of $\mathrm{Li}_{3} \mathrm{IrO}_{4}$ (Figure 1c) exhibits three features at $527.9,529.1$, and $531.7 \mathrm{eV}$, corresponding to transitions to unoccupied $\mathrm{O} 2 p$-Ir $5 d$ hybridized states (Supplementary Note 1). The broad features above $535 \mathrm{eV}$ arise from O $2 p$-Ir $6 s, p$ states and the multiple scattering events upon photoionization. The spectrum was measured in partial fluorescence yield (PFY) to maximize signals from the interior of the electrode because the surface signals (total electron yield, TEY) were dominated by a peak at $\sim 533.7 \mathrm{eV}$ (Figure S2) ascribed to $\mathrm{Li}_{2} \mathrm{CO}_{3}$ impurities. ${ }^{29}$ The surface showed a notable sensitivity to air, with batches where contamination was enough to produce these signals, albeit at much lower relative intensity, even in fluorescence yield measurements (Figure S2).

The $\mathrm{O}$ pre-edge $(<535 \mathrm{eV})$ signals reflect a splitting of the $\mathrm{O} 2 p$-Ir $5 d$ states in a distorted octahedral ligand field, with $\pi$ and $\sigma$ interactions appearing below and above $530 \mathrm{eV}$, respectively. These interactions would give rise to $t_{2 g}$ and $e_{g}$ states, respectively, in an undistorted octahedral field; they will be labelled as such for brevity. The qualitatively lower pre-edge intensity below than above $530 \mathrm{eV}$ reflects the ratio of unoccupied states in the lowspin $\mathrm{d}^{4}$ configuration of $\operatorname{Ir}(\mathrm{V})$ and differences in the extent of overlap between $\operatorname{Ir} 5 d$ and $\mathrm{O} 2 p$ states. Measurements of zero-field cooled magnetization between 25 and $300 \mathrm{~K}$ showed weak paramagnetism with $\mu_{\text {eff }}=0.84 \mu_{\mathrm{B}} / \mathrm{Ir}$ (Figure S1b), similar to other $\operatorname{Ir}(\mathrm{V})$ phases (Supplementary Note $\mathrm{S} 4)^{30,31}$ and consistent with previous EPR measurements. ${ }^{19}$

The additional splitting observed in the $\mathrm{O}$ pre-edge, around $1.2 \mathrm{eV}$, appeared to be beyond the range expected from spin-orbit coupling, which has been reported as frustrated in other $\operatorname{Ir}(\mathrm{V})$ 
oxides. ${ }^{31}$ Its origin was probed by X-ray emission spectroscopy (XES) through selective excitations at 527.85 and $529.05 \mathrm{eV}$ (Figure 1b). XES probes transitions from occupied O $2 p$ states to fill the $1 s$ core-hole (Supplementary Note 2). Excitation at $529.05 \mathrm{eV}$ induced a blueshift of $0.6 \mathrm{eV}$ on the main emission peak compared to $527.85 \mathrm{eV}$ excitation, accompanied by a broadening of the shoulder at higher energy (Figures $1 \mathrm{~b}$ and S3). This behavior indicates the existence of two different non-equivalent sites for $\mathrm{O}$ in the crystal structure, connected to two and one distorted $\mathrm{IrO}_{6}$ octahedra. ${ }^{19}$ The blueshift was much smaller than the splitting of the two corresponding pre-edge peaks, reflecting a different core-hole screening for the two sites. Excitations at higher energy only induced subtle shifts reflecting the balance between exciting the two $\mathrm{O}$ sites with different binding energy.

Two and three localized electron lone pairs, respectively, were revealed by the computed Electron Localization Functions (ELF) of the two $\mathrm{O}$ sites $\left(\mathrm{O}_{2 \mathrm{LP}}\right.$ and $\mathrm{O}_{3 \mathrm{LP}}$, hereafter, where $\mathrm{LP}=$ electron lone pairs, Figure 2a), in line with the octet rule (Figure S4) ${ }^{26}$ The lone pairs of $\mathrm{O}_{3 \mathrm{LP}}$ lie higher than $\mathrm{O}_{2 \mathrm{LP}}$ in the computed density of states of $\mathrm{Li}_{3} \mathrm{IrO}_{4}$ (Figure 2b), in agreement with their computed Madelung potentials $\left(\mathcal{M}_{O}\right)$. The simulated XAS, assuming a structure with $\mathrm{Li} / \mathrm{Ir}$ ordering in the transition metal layers, qualitatively reproduced the three main regions observed experimentally (Figure $2 \mathrm{c}$ ). The significant splitting of the hybridized $t_{2 \mathrm{~g}}$ states could only be obtained when the core-level shift was included in the calculations, and became even more pronounced when $\mathrm{Li} / \mathrm{Ir}$ intralayer disorder was introduced, according to the experimentally observed structure. ${ }^{19}$ Such disorder affects the distribution of $\mathrm{O}_{2 \mathrm{LP}}$ and $\mathrm{O}_{3 \mathrm{LP}}$ in each $\mathrm{IrO}_{6}$ octahedron (Table S1), which splits the bands and shrinks the band gap (Figure 2b). All in all, the XAS spectrum can be viewed as the sum of the individual spectra of $\mathrm{O}_{3 L P}$ and $\mathrm{O}_{2 L P}$, with the former being responsible for the features at lower energy, in perfect agreement with its higher 
electronic charge (i.e. less covalent bonds to Ir).

Changes at $\boldsymbol{O}$ states upon delithiation. Deintercalation of the first $2 \mathrm{~mol}$ of $\mathrm{Li}$ from $\mathrm{Li}_{3} \mathrm{IrO}_{4}$ induced minor changes in $\mu_{\mathrm{eff}}$, to 0.595 and $1.178 \mu_{\mathrm{B}} / \mathrm{Ir}$ at $\mathrm{x}=2$ and 1 (in $\mathrm{Li}_{x} \mathrm{IrO}_{4}$, Figures S1c and S1d), reflecting a relatively weak paramagnetism that does not quite reach values expected even for $\mathrm{S}=1 / 2$. The fine structure of the $\mathrm{O} \mathrm{K}$-edge XAS above $535 \mathrm{eV}$ was modified, with the centroid shifting toward high energy compared to the pristine state (Figures 1c and S5). The centroid of the XES showed also blueshifted at all excitations except $528.55 \mathrm{eV}$. The changes were most pronounced with the first Li removal. All these changes were assigned to the lowering of the energy of the $\mathrm{O} 1 s$ states due to an increase in average $\mathrm{Z}_{\mathrm{eff}}$ (effective nuclear charge) resulting from depletion of electron density of $\mathrm{O}$.

The most drastic changes in the $\mathrm{O}$ K-edge XAS took place below $530 \mathrm{eV}$. There was a dominant peak at $528.5 \mathrm{eV}$ showing a shoulder at $527.7 \mathrm{eV}$ in both $\mathrm{x}=2$ and $\mathrm{x}=1$ (Figure 1c), a change in both position and, especially, relative intensity of the maxima compared to the pristine state. Their increased overlap prevented selective excitation of $\mathrm{O}_{2 L P}$ and $\mathrm{O}_{3 \mathrm{LP}}$ in the XES (Figure 1b). Overall, the integrated intensity under the pre-edge XAS signals below $530 \mathrm{eV}$ significantly increased from pristine to $\mathrm{x}=2$ (Figure 1e), but remained comparatively unchanged between $\mathrm{x}=$ 2 and $\mathrm{x}=1$ (Figure 1e). Above $530 \mathrm{eV}$, the onset of the third pre-edge peak was static (Figures 1c and 1d), but its area progressively increased through a significant broadening toward higher energy (Figure 1c). The net result was a rather proportional increase in its integrated intensity with delithiation (Figure 1f). These observations indicate an increase in unoccupied states with $\mathrm{O}$ character upon oxidation.

Computational analysis of the changes in O K-edge XAS (Figure 3) revealed that, upon oxidation from pristine to $\mathrm{x}=2$, the existence of $\mathrm{Li} / \mathrm{Ir}$ intralayer disorder shifts the charge 
compensation from only depleting O $2 p$-Ir $5 d$ states (i.e., classical formal oxidation of cations, $\mathrm{CR}$ ) in the ideal lattice to also significant involving one of the three lone pairs of $\mathrm{O}_{3 \mathrm{LP}}$ (Figure S6). This prediction is consistent with $\mathrm{CR}$ only being observed up to $\mathrm{Li}_{2.5} \mathrm{IrO}_{4}$ via $\mathrm{Ir} \mathrm{L}_{\mathrm{III}}$-edge XAS. ${ }^{19}$ This effect can be visualized in the ELFs of one of the possible disordered structures of $\mathrm{Li}_{2} \mathrm{IrO}_{4}$ (Figure 3). Similar results were obtained for other patterns of Li/Ir disorder, with $\mathrm{O}_{2 \mathrm{LP}}$ systematically participating to a much lesser extent than $\mathrm{O}_{3 \mathrm{LP}}$ (Figure S6), consistent with the relative positioning of their lone-pair states in the pDOS (Figure 2). This change in electronic structure perfectly reproduces the change in the ratio of intensity below $530 \mathrm{eV}$ in the XAS spectrum of $\mathrm{Li}_{2} \mathrm{IrO}_{4}$ (Figure 3), as the newly depleted $\mathrm{O}_{3 \mathrm{LP}} \rightarrow^{2 \mathrm{LP}}$ states (orange $\mathrm{O}$ connected to $1 \mathrm{Ir}$ ) showed similar energy to $\mathrm{O}_{2 \mathrm{LP}}$ (red $\mathrm{O}$ connected to $2 \mathrm{Ir}$ ). Upon further oxidation to $\mathrm{x}=1$, the initial $\mathrm{O}_{2 \mathrm{LP}}$ states in $\mathrm{Li}_{3} \mathrm{IrO}_{4}$ became more involved, yet still to a lower extent than $\mathrm{O}_{3 \mathrm{LP}}$. The computations revealed that the oxidation of the two $\mathrm{O}_{2 \mathrm{LP}}$ between two $\mathrm{IrO}_{6}$ octahedra (red oxygens in Figures 2 and 3) decreased their bond length toward $2.4 \AA$. In contrast, $\mathrm{O}_{3 \mathrm{LP}}$ tended to shorten their Ir-O length upon lone-pair depletion, to below $1.9 \AA \AA^{19}$ most likely leading to a higher bond order, as previously proposed for $\mathrm{Li}_{2-\mathrm{x}} \mathrm{Ir}_{1-\mathrm{y}} \mathrm{Sn}_{\mathrm{y}} \mathrm{O}_{3} \cdot{ }^{24}$ The collapse of the two signals below $530 \mathrm{eV}$ is ascribed to all $\mathrm{O}$ becoming electronically equivalent (Figure 3). The remaining shoulder at low energy in the experimental spectra could arise from the incomplete oxidation of the electrode to $\mathrm{x}=1$, since the experimental cut-off was set assuming a faradaic efficiency of $100 \%$.

The O K-edge XAS of the electrode oxidized to $4.5 \mathrm{~V}$, associated with the irreversible transition to amorphous $\mathrm{IrO}_{3},{ }^{19}$ possessed a single peak at $528.6 \mathrm{eV}$, with no shoulders at lower energy and a significant asymmetry spanning toward $530 \mathrm{eV}$ (Figure 1c). The integrated (relative) area under this single signal was slightly greater than $x=1(\sim 2.4 \%$, Figure 1e). Similarly, the 
centroid of the feature between 530 and $535 \mathrm{eV}$ blue shifted by $0.3 \mathrm{eV}$ with an increase in the integrated area that qualitatively followed the trend starting from $x=3$ (Figure 1f). Blueshifts with respect to $\mathrm{x}=1$ were also observed in both the inflection point in the main absorption edge (Figure S5) and all $\mathrm{O} \mathrm{K \alpha}$ emission spectra (Figure 1b). These changes indicate a shift of the $\mathrm{O} 1 \mathrm{~s}$ level to lower energy, signifying an increased $\mathrm{Z}_{\mathrm{eff}},{ }^{32,33}$ consistent with the strong participation of the anions in the compensation of the process of oxidation. Overall, all spectra became broader at this high state of charge, as expected from amorphization. ${ }^{19}$

Chemical reversibility of LOR. While other oxides have conclusively been shown to display unconventional LOR activity upon delithiation, many display chemical hysteresis, whereby subsequent reduction does not return the compound to its original crystal and/or electronic structure. ${ }^{16,17,34-37}$ Since the final step of $\mathrm{O}_{2}$ loss is irreversible, ${ }^{19}$ we will only elaborate on the reduction of an electrode charged to $\mathrm{x}=1$, or $\mathrm{LiIrO}_{4}$. Its reduction to $2.6 \mathrm{~V}$ produced a capacity equivalent to $1.5 \mathrm{~mol}$ of $\mathrm{Li}$, and almost completely restored the $\mathrm{O} \mathrm{K}$-edge XAS and $\mathrm{O} \mathrm{K} \alpha \mathrm{XES}$ to the pristine state (Figure 1). A shoulder at high energy in the XES, which vanished gradually upon delithiation, became prominent again after, suggesting that it is correlated to the (de)intercalation process. All in all, the $\mathrm{O} p$ states before and after a full cycle were almost identical.

Implications for the existence and mechanism of LOR. The evolution of the $\mathrm{O}$ spectra clearly demonstrates the participation of ligand states in the charge compensation of the delithiation of $\mathrm{Li}_{3} \mathrm{IrO}_{4}$. In particular, the results reveal the shifting contribution from $\mathrm{O}_{3 \mathrm{LP}}$, which are at higher energy in the pristine state, to $\mathrm{O}_{2 \mathrm{LP}}$ as the delithiation progressed beyond $1 \mathrm{~mol}$ of Li. In the preceding study by Perez et al., Ir $\mathrm{L}_{\mathrm{III}}$-edge XAS of the same states revealed only a minor change in the early stages of the reaction, which was essentially arrested after about 0.5 
mol of $\mathrm{Li}$ were removed from $\mathrm{Li}_{3} \mathrm{IrO}_{4} \cdot{ }^{19}$ Our DFT calculations show that this effect is related to the statistical $\mathrm{Li} / \mathrm{Ir}$ disorder within the transition metal layer of the oxide. Since $\mathrm{O}_{2}$ loss does not occur when the oxidation is limited to $\mathrm{x}=1,{ }^{19}$ we can indisputably ascribe the behavior of $\mathrm{Li}_{3} \mathrm{IrO}_{4}-\mathrm{Li}_{1} \mathrm{IrO}_{4}$ to $\mathrm{LOR}$, beyond the bounds of $\mathrm{CR} .{ }^{36}$ Interestingly, although evolution of $\mathrm{O}_{2}$ accompanied by amorphization is induced when the last $1 / 3$ of $\mathrm{Li}$ are removed, the $\mathrm{O}$ spectra indicate that ligands in a- $\mathrm{IrO}_{3}$ remained highly oxidized despite the evolution of $\mathrm{O}_{2}{ }^{19}$

In other Li-rich transition metal oxides, LOR is most often associated with the onset of a sharp feature in resonant inelastic X-ray scattering (RIXS) maps, located at $\sim 523 \mathrm{eV}$ emission when the excitation was at $\sim 531 \mathrm{eV} .^{23,24,27,28}$ RIXS maps were also measured for $\mathrm{Li}_{\mathrm{X}} \mathrm{IrO}_{4}$ (Figure 4), with an estimated flux $\left(5 \times 10^{10}-1 \times 10^{11}\right.$ photons/s), below the reported threshold of sample damage reported in the literature. ${ }^{38}$ There was an increase in the dispersion of emitted states ( $x$ axis in Figure 4), as well as the relative intensity of the elastic peak for all oxidized phases. This enhancement has been associated in very recent work to $\eta^{1}-\mathrm{O}_{2}$ units. ${ }^{39,40}$ Furthermore, delithiation from $\mathrm{Li}_{3} \mathrm{IrO}_{4}$ did not produce any features at $\sim 523 \mathrm{eV}$ emission for a $\sim 531 \mathrm{eV}$ excitation. This feature was concurrent with the existence of out-of-plane Sn migration in layered $\mathrm{Li}_{2-x} \mathrm{Ir}_{1-y} \mathrm{Sn}_{y} \mathrm{O}_{3}$, which only displays LOR at y $>0 .{ }^{24,41}$ It has recently been specifically ascribed to the formation of short $\mathrm{O}-\mathrm{O}$ bridges between $\mathrm{Ir}$ atoms when these defects are introduced. $^{42}$ Most importantly, it is also observed in conventional layered oxides, ${ }^{43,44}$ where the charge compensation could formally be accounted by conventional CR. In that case, the appearance of the loss feature at $523 \mathrm{eV}$ correlates with the collapse of the interlayer distance, concurrent with a deformation of the octahedral coordination of the transition metals. ${ }^{43}$ No evidence of Ir migration exists for $\mathrm{Li}_{\mathrm{X}} \mathrm{IrO}_{4}$ before amorphization, ${ }^{19}$ consistent with a predicted low driving force. ${ }^{24}$ Formation of short peroxo $(\mathrm{O}-\mathrm{O})$ bridges between $\mathrm{Ir}^{24}$ is also not predicted 
by our models. Lastly, the change in the interlayer distance is very small up to $\mathrm{x}=1 .{ }^{19}$ Therefore, our work indicates that: i) LOR is not uniquely associated with specific loss features in the RIXS maps, ii) spectroscopic evaluation of both metals and ligands is required to determine its existence, and iii) different processes may fall under the umbrella of LOR with subtle differences in structural and electronic features.

The DFT calculations presented here indicate that delithiation is compensated by $\mathrm{O} 2 p$ states that are initially non-bonding. The $\mathrm{IrO}_{6}$ octahedra are predicted to distort to form short Ir-O bonds, ${ }^{24}$ and introduce O-O distances at $\sim 2.4 \AA$, characteristic of the so-called reductive coupling mechanism. ${ }^{25,}{ }^{45}$ The principle by which LOR occurs in $\mathrm{Li}_{3} \mathrm{IrO}_{4}$ is consistent with $\mathrm{Li}_{2-\mathrm{x}} \mathrm{Ir}_{1-}$ ${ }_{y} \mathrm{Sn}_{y} \mathrm{O}_{3}:{ }^{24}$ it involves a high density of uncoordinated $\mathrm{O} 2 p$ states, or lone pairs. However, unlike $\mathrm{Li}_{2-x} \mathrm{Ir}_{1-y} \mathrm{Sn}_{y} \mathrm{O}_{3}$, the high $\mathrm{O} / \mathrm{Ir}$ ratio of $\mathrm{Li}_{3} \mathrm{IrO}_{4}$ generates sufficient non-bonding states in its pristine state, as originally predicted by Xie et al. ${ }^{25}$ Therefore, it does not require out-of-plane migration of heavy cations like $\mathrm{Sn}(\mathrm{IV}),{ }^{24}$ a prominent driver of voltage hysteresis and irreversibility. ${ }^{42,} 46$ The LOR is extremely reversible if delithiation is stopped at $\mathrm{Li}_{1} \mathrm{IrO}_{4}$, with the material returning to its initial state. This behavior distinguishes $\mathrm{Li}_{3} \mathrm{IrO}_{4}$ from other lithiated oxides where LOR unlocks a different pathway involving conventional $\mathrm{CR},{ }^{17,34,35,37,47}$ including parent $\mathrm{Li}_{3} \mathrm{RuO}_{4}{ }^{36}$, 48

This report clearly pinpoints the $\mathrm{O}$ states that enable the shift of the redox centers to the ligands. While $\alpha-\mathrm{Li}_{2} \mathrm{IrO}_{3}$ also possesses two non-equivalent $\mathrm{O}$ sites, similar measurements did not find any significant difference in their contribution to charge compensation. ${ }^{41}$. This fact convincingly reinforces that $L O R$ requires $\mathrm{O}$ sites like $\mathrm{O}_{3 \mathrm{LP}}$, namely with connectivity to only one transition metal, to avoid cation migration, which is not favorable for Ir. These sites are present in $\mathrm{Li}_{3} \mathrm{IrO}_{4}$, but not $\alpha-\mathrm{Li}_{2} \mathrm{IrO}_{3},{ }^{49}$ or similar honeycomb oxides. At the same time, 
comparison with other $\mathrm{Li}_{3} T M \mathrm{O}_{4}(T M=\mathrm{Nb}$ or $\mathrm{V})$ emphasizes that connectivity to a $d^{\mathrm{n}}(\mathrm{n}>0)$ transition metal is crucial, as it allows hybridization that stabilizes the structure and renders it reversible. We have also proposed ${ }^{22,25,26}$ that oxides having no empty d-orbitals to enable rehybridization should undergo irreversible reactions with $\mathrm{O}_{2}$ release. Further disentangling the role of Ir, in contrast to other $d^{\mathrm{n}}$ metals such as $\mathrm{Ru},{ }^{36}$ as enabling effective rehybridization ${ }^{26}$ and/or preventing the formation of defects ${ }^{42}$ is indispensable if this reversible reactivity is to be mimicked with base metals, a required step for this concept to have technological impact in highenergy Li-ion batteries. 

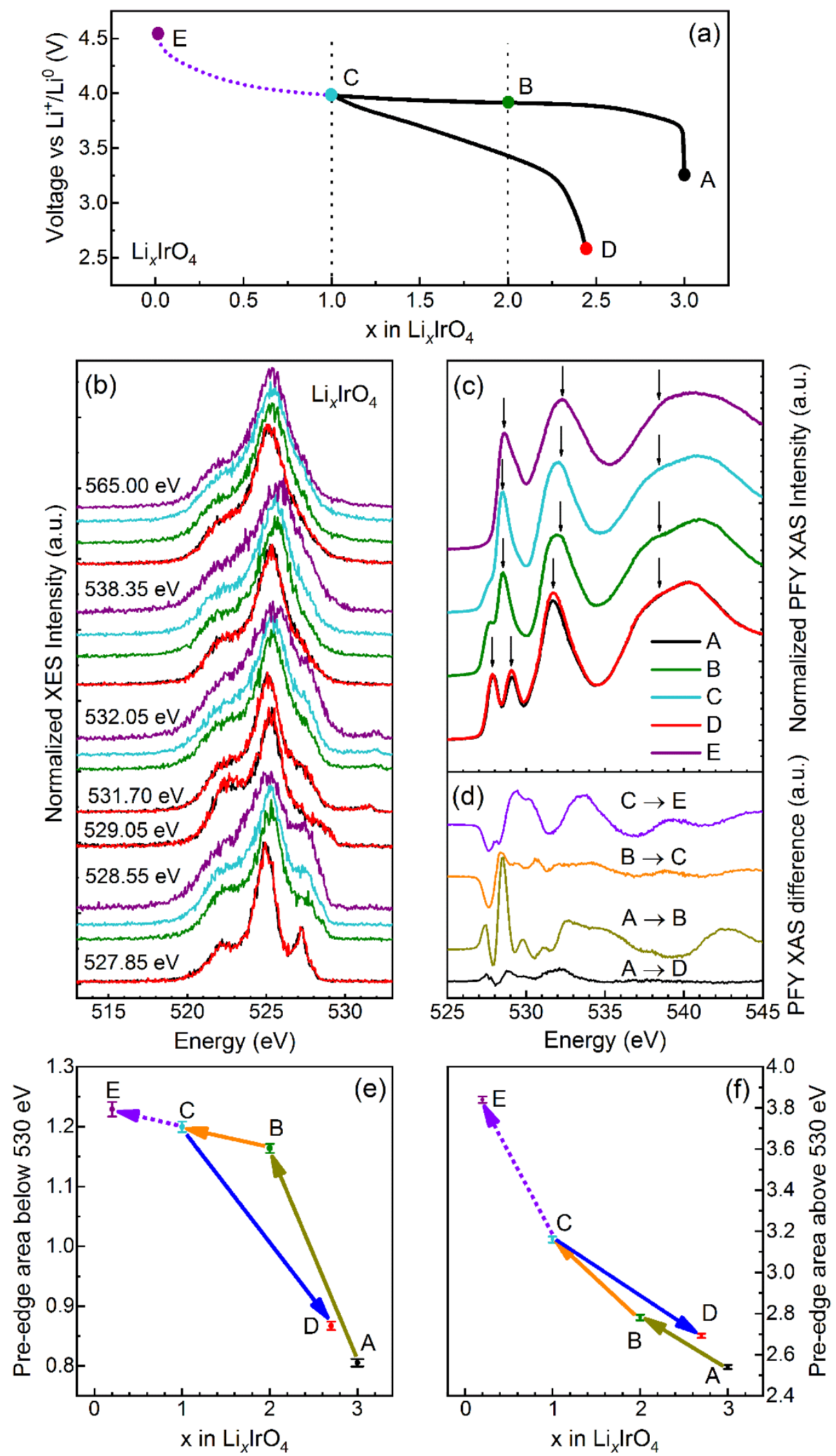
Figure 1. (a) Voltage-composition profile of $\mathrm{Li}_{3} \mathrm{IrO}_{4}$. The states of interest for ex situ analysis are marked, with dotted lines indicating the compositions $\mathrm{Li}_{2} \mathrm{IrO}_{4}$ and $\mathrm{Li}_{1} \mathrm{IrO}_{4}$. (b) Ex situ $\mathrm{O} \mathrm{K \alpha}$ XES at specific excitation energies displayed on the left. (c) Ex situ O K-edge XAS measured in PFY mode, with arrows indicating energies selected for XES. (d) Differential XAS between the states indicated. Integrated intensity under the pre-edge region (e) between 525 and $530 \mathrm{eV}\left(\mathrm{t}_{2 \mathrm{~g}}\right.$ region in an undistorted ligand field) and (f) between 530 and $535 \mathrm{eV}\left(\mathrm{e}_{\mathrm{g}}\right)$, measured from (c).

(a) Electron localization function (ELF)

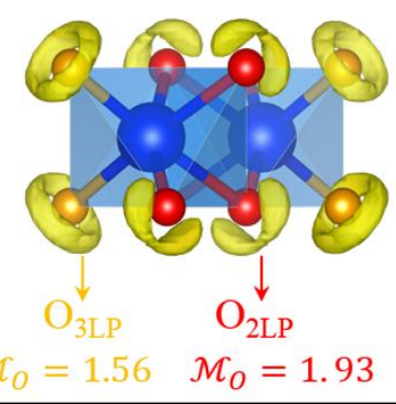

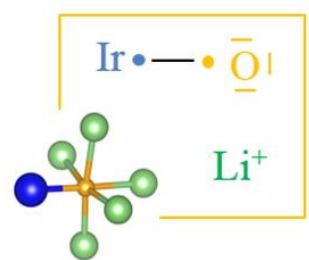

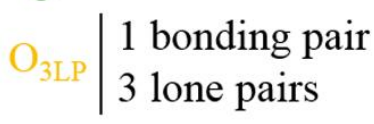

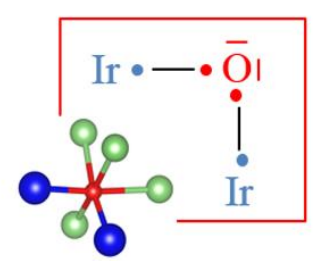

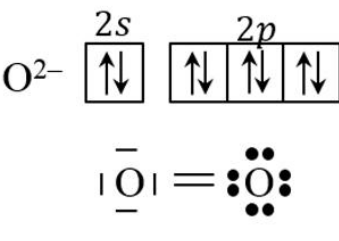

\begin{tabular}{l|l}
$\mathrm{O}_{2 L P}$ & $\begin{array}{l}2 \text { bonding pairs } \\
2 \text { lone pairs }\end{array}$
\end{tabular} (b) Density of States $\mathrm{Li}_{3} \mathrm{IrO}_{4}$
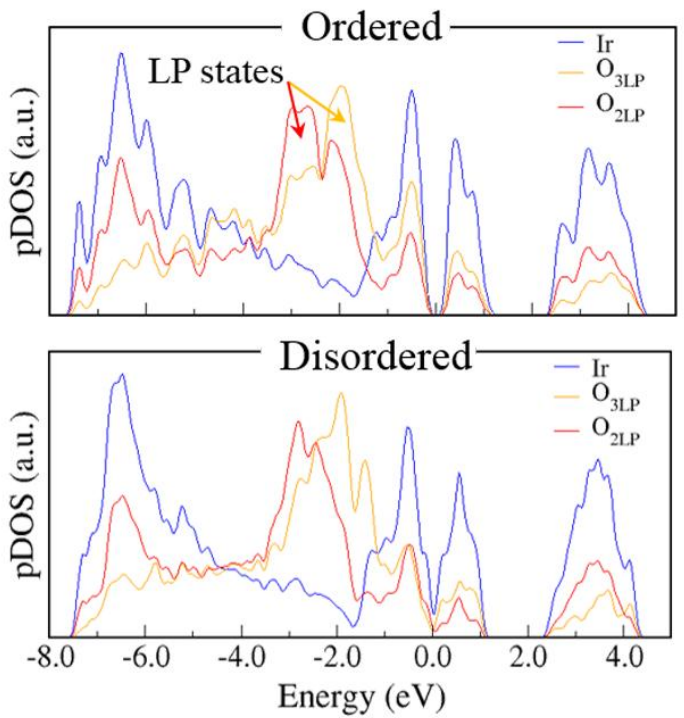

(c) Simulated XAS $\mathrm{Li}_{3} \mathrm{IrO}_{4}$

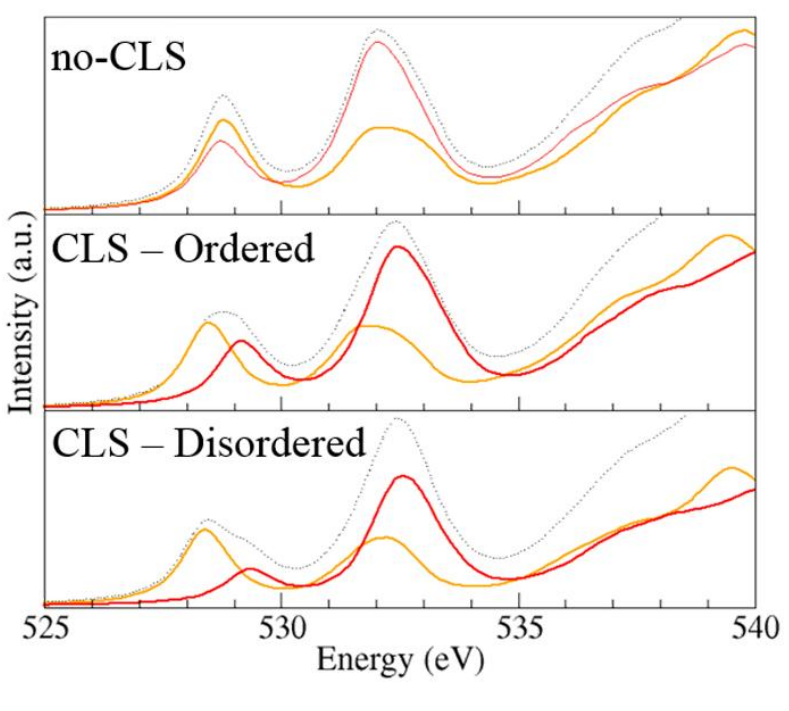

Figure 2. (a) Electron localization Function (ELF), computed by DFT, for $\mathrm{Li}_{3} \mathrm{IrO}_{4}$, showing 2 
and 3 lone-pairs around $\mathrm{O}_{2 L P}$ (red) and $\mathrm{O}_{3 L P}$ (orange), respectively, in agreement with their different local environments. The Lewis structures of the two different oxygen bonding environments obey the octet rule stating that $\mathrm{O}^{2-}$ is stable with four electron-pairs distributed into $n$ bonding-pairs (involved in Ir-O) and $4-n$ lone-pairs (un-hybridized to Ir). (b) Atomprojected density of states (pDOS) showing a shift in energy of $\mathrm{O}_{3 \mathrm{LP}}$ lone-pair states with respect to $\mathrm{O}_{2 \mathrm{LP}}$ due to a lower Madelung potential $\left(\mathcal{M}_{O}\right)$. A Mott insulator electronic ground-state is obtained for $\mathrm{Li}_{3} \mathrm{IrO}_{4}$, with a small energy gap for the $\mathrm{Li} / \mathrm{Ir}$ ordered structure that cancels out when disorder is introduced in the model. (c) Simulated XAS spectra of the ordered and disordered $\mathrm{Li}_{3} \mathrm{IrO}_{4}$ structures (see Supplementary Information for details) with or without including corelevel shift in the calculations. The XAS projected on the $\mathrm{O}_{3 \mathrm{LP}}$ and $\mathrm{O}_{2 \mathrm{LP}}$ absorbing species showing that the splitting of the first excitation peak arises from the different oxygen electronic structures, the $\mathrm{O}_{3 L P} 1 \mathrm{~s}$ core-level having a lower binding energy than $\mathrm{O}_{2 \mathrm{LP}} 1 \mathrm{~s}$.

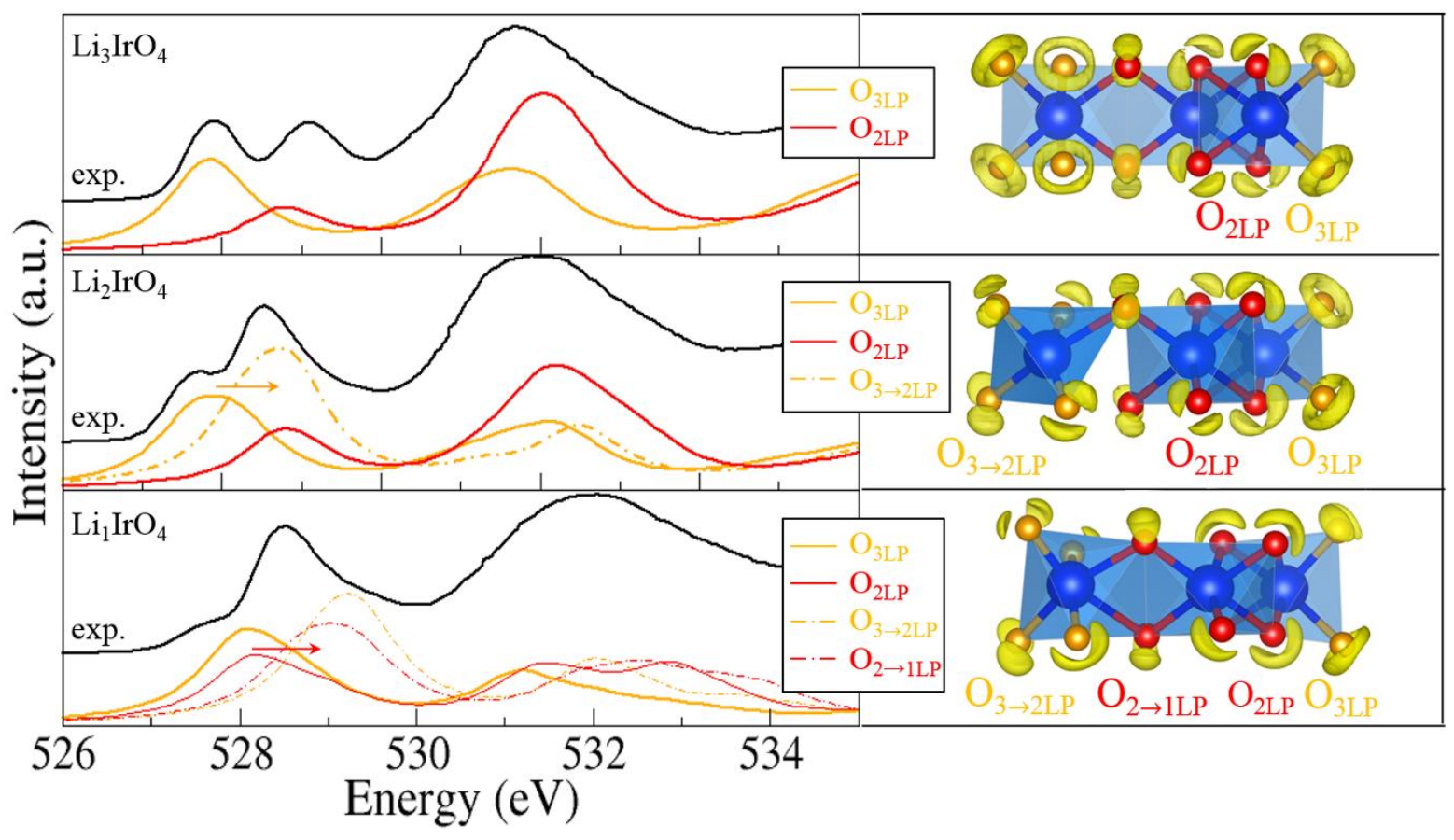


Figure 3. (left) Simulated vs. experimental XAS spectra for $\mathrm{Li}_{\mathrm{x}} \mathrm{IrO}_{4}(\mathrm{x}=3,2,1)$, showing that the evolution is due to the progressive participation of the two $\mathrm{O}$ sites in the oxidation. (right) Electron localization functions computed for each structure and confirming the main oxidation of $\mathrm{O}_{3 L P}$, to produce $\mathrm{O}_{3 \mathrm{LP} \rightarrow 2 \mathrm{LP}}$, (orange) from $\mathrm{x}=3$ to $\mathrm{x}=2$ and a mixed oxidation of $\mathrm{O}_{3 \mathrm{LP} \rightarrow 2 \mathrm{LP}}$ (orange) and $\mathrm{O}_{2 \mathrm{LP}}$, to produce $\mathrm{O}_{2 \mathrm{LP} \rightarrow 1 \mathrm{LP}}$, (red) from $\mathrm{x}=2$ to $\mathrm{x}=1$. Other results with different $\mathrm{Li} / \mathrm{Ir}$ disorder are shown in Figure S8.
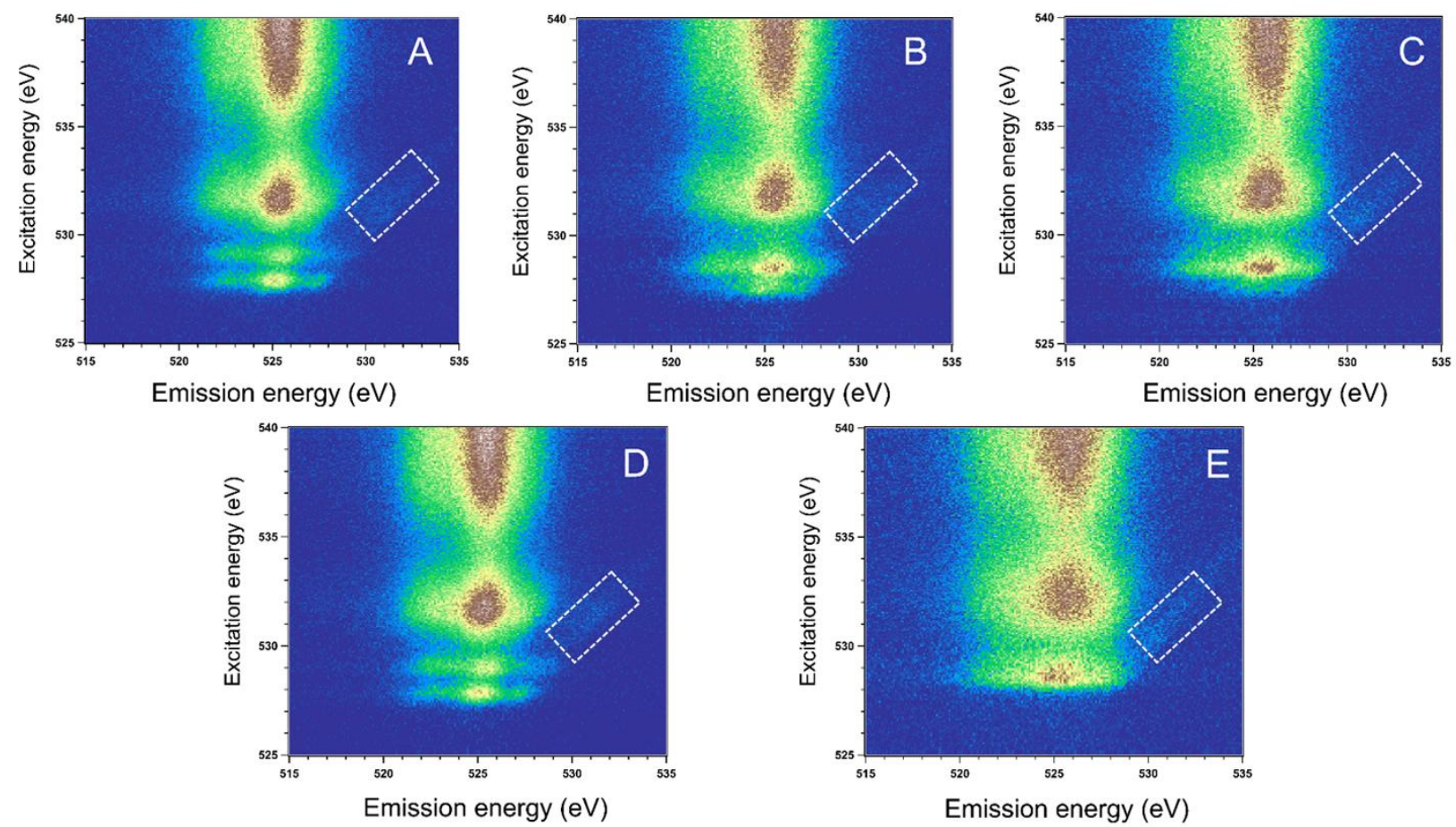

Figure 4. Ex situ $\mathrm{O}$ K-edge RIXS maps of $\mathrm{Li}_{3} \mathrm{IrO}_{4}$ at the different electrochemical states indicated. The white rectangular regions identify the elastic peak. 


\section{Methods}

See the Supplementary Information for details of the materials and methods.

\section{Acknowledgements}

This material is based upon work supported by the National Science Foundation under Grant No. DMR-1809372. This research used resources of the Advanced Photon Source, a U.S. Department of Energy (DOE) Office of Science User Facility operated for the DOE Office of Science by Argonne National Laboratory under Contract No. DE-AC02-06CH11357. Part or all of the research described in this paper was performed at the Canadian Light Source, a national research facility of the University of Saskatchewan, which is supported by the Canada Foundation for Innovation (CFI), the Natural Sciences and Engineering Research Council (NSERC), the National Research Council (NRC), the Canadian Institutes of Health Research (CIHR), the Government of Saskatchewan, and the University of Saskatchewan.

\section{References}

1. Dunn, B.; Kamath, H.; Tarascon, J.-M., Electrical Energy Storage for the Grid: A Battery of Choices. Science 2011, 334, (6058), 928-935.

2. Goodenough, J. B.; Kim, Y., Challenges for Rechargeable Li Batteries. Chem. Mater. 2010, 22, (3), 587-603.

3. Mizushima, K.; Jones, P. C.; Wiseman, P. J.; Goodenough, J. B., $\mathrm{Li}_{\mathrm{x}} \mathrm{CoO}_{2}(0<\mathrm{x}<-1)$ : A new cathode material for batteries of high energy density. Mater. Res. Bull. 1980, 15, (6), 783789. 
4. Lu, Z.; MacNeil, D. D.; Dahn, J. R., Layered Li[Ni $\left.\mathrm{No}_{1-2 \mathrm{x}} \mathrm{Mn}_{\mathrm{x}}\right] \mathrm{O}_{2}$ Cathode Materials for Lithium-Ion Batteries. Electrochem. Solid-State Lett. 2001, 4, (12), A200-A203.

5. Tsutomu, O.; Yoshinari, M., Layered Lithium Insertion Material of $\mathrm{LiCo}_{1 / 3} \mathrm{Ni}_{1 / 3} \mathrm{Mn}_{1 / 3} \mathrm{O}_{2}$ for Lithium-Ion Batteries. Chem. Lett. 2001, 30, (7), 642-643.

6. Yoshizawa, H.; Ohzuku, T., An application of lithium cobalt nickel manganese oxide to high-power and high-energy density lithium-ion batteries. J. Power Sources 2007, 174, (2), 813817.

7. Lu, Z.; MacNeil, D. D.; Dahn, J. R., Layered Cathode Materials $\mathrm{Li}\left[\mathrm{Ni}_{\mathrm{x}} \mathrm{Li}_{1 / 3-2 \mathrm{x} / 3} \mathrm{Mn}_{2 / 3-\mathrm{x} / 3}\right] \mathrm{O}_{2}$ for Lithium-Ion Batteries. Electrochem. Solid-State Lett. 2001, 4, (11), A191.

8. Johnson, C. S.; Kim, J. S.; Lefief, C.; Li, N.; Vaughey, J. T.; Thackeray, M. M., The significance of the $\mathrm{Li}_{2} \mathrm{MnO}_{3}$ component in 'composite' $\mathrm{xLi}_{2} \mathrm{MnO}_{3} \cdot(1-\mathrm{x}) \mathrm{LiMn}_{0.5} \mathrm{Ni}_{0.5} \mathrm{O}_{2}$ electrodes. Electrochem. Commun. 2004, 6, (10), 1085-1091.

9. Thackeray, M. M.; Kang, S. H.; Johnson, C. S.; Vaughey, J. T.; Hackney, S. A., Comments on the structural complexity of lithium-rich $\mathrm{Li}_{1+\mathrm{x}} \mathrm{M}_{1-\mathrm{x}} \mathrm{O}_{2}$ electrodes $(\mathrm{M}=\mathrm{Mn}, \mathrm{Ni}, \mathrm{Co})$ for lithium batteries. Electrochem. Commun. 2006, 8, (9), 1531-1538.

10. Thackeray, M. M.; Kang, S.-H.; Johnson, C. S.; Vaughey, J. T.; Benedek, R.; Hackney, S. A., $\mathrm{Li}_{2} \mathrm{MnO}_{3}$-stabilized $\mathrm{LiMO}_{2}(\mathrm{M}=\mathrm{Mn}, \mathrm{Ni}, \mathrm{Co})$ electrodes for lithium-ion batteries. J. Mater. Chem. 2007, 17, (30), 3112.

11. Johnson, C. S.; Li, N.; Lefief, C.; Vaughey, J. T.; Thackeray, M. M., Synthesis, Characterization and Electrochemistry of Lithium Battery Electrodes: $\mathrm{xLi}_{2} \mathrm{MnO}_{3} \cdot(1 \quad-$ $\mathrm{x}) \mathrm{LiMn}_{0.333} \mathrm{Ni}_{0.333} \mathrm{Co}_{0.333} \mathrm{O}_{2}(0 \leqslant \mathrm{x} \leqslant 0.7)$. Chem. Mater. Chemistry of Materials 2008, 20, (19), 6095-6106. 
12. Rozier, P.; Tarascon, J. M., Review-Li-Rich Layered Oxide Cathodes for NextGeneration Li-Ion Batteries: Chances and Challenges. J. Electrochem. Soc. 2015, 162, (14), A2490-A2499.

13. Oishi, M.; Yamanaka, K.; Watanabe, I.; Shimoda, K.; Matsunaga, T.; Arai, H.; Ukyo, Y.; Uchimoto, Y.; Ogumi, Z.; Ohta, T., Direct observation of reversible oxygen anion redox reaction in Li-rich manganese oxide, $\mathrm{Li}_{2} \mathrm{MnO}_{3}$, studied by soft X-ray absorption spectroscopy. J. Mater. Chem. A 2016, 4, (23), 9293-9302.

14. Luo, K.; Roberts, M. R.; Hao, R.; Guerrini, N.; Pickup, D. M.; Liu, Y. S.; Edstrom, K.; Guo, J.; Chadwick, A. V.; Duda, L. C.; Bruce, P. G., Charge-compensation in 3d-transitionmetal-oxide intercalation cathodes through the generation of localized electron holes on oxygen. Nat. Chem. 2016, 8, (7), 684-91.

15. Yabuuchi, N.; Yoshii, K.; Myung, S.-T.; Nakai, I.; Komaba, S., Detailed Studies of a High-Capacity Electrode Material for Rechargeable Batteries, $\mathrm{Li}_{2} \mathrm{MnO}_{3}-\mathrm{LiCo}_{1 / 3} \mathrm{Ni}_{1 / 3} \mathrm{Mn}_{1 / 3} \mathrm{O}_{2} . J$. Am. Chem. Soc. 2011, 133, (12), 4404-4419.

16. Jacquet, Q.; Iadecola, A.; Saubanère, M.; Li, H.; Berg, E. J.; Rousse, G.; Cabana, J.; Doublet, M.-L.; Tarascon, J.-M., Charge Transfer Band Gap as an Indicator of Hysteresis in LiDisordered Rock Salt Cathodes for Li-Ion Batteries. J. Am. Chem. Soc. 2019, 141, (29), 1145211464.

17. Assat, G.; Foix, D.; Delacourt, C.; Iadecola, A.; Dedryvère, R.; Tarascon, J.-M., Fundamental interplay between anionic/cationic redox governing the kinetics and thermodynamics of lithium-rich cathodes. Nat. Commun. 2017, 8, (1), 2219.

18. McCalla, E.; Abakumov, A. M.; Saubanère, M.; Foix, D.; Berg, E. J.; Rousse, G.; Doublet, M.-L.; Gonbeau, D.; Novák, P.; Van Tendeloo, G.; Dominko, R.; Tarascon, J.-M., 
Visualization of O-O peroxo-like dimers in high-capacity layered oxides for Li-ion batteries. Science 2015, 350, (6267), 1516-1521.

19. Perez, A. J.; Jacquet, Q.; Batuk, D.; Iadecola, A.; Saubanère, M.; Rousse, G.; Larcher, D.; Vezin, H.; Doublet, M.-L.; Tarascon, J.-M., Approaching the limits of cationic and anionic electrochemical activity with the Li-rich layered rocksalt $\mathrm{Li}_{3} \mathrm{IrO}_{4}$. Nat. Energy 2017, 2, (12), 954962.

20. Pearce, P. E.; Perez, A. J.; Rousse, G.; Saubanère, M.; Batuk, D.; Foix, D.; McCalla, E.; Abakumov, A. M.; Van Tendeloo, G.; Doublet, M.-L.; Tarascon, J.-M., Evidence for anionic redox activity in a tridimensional-ordered Li-rich positive electrode $\beta-\mathrm{Li}_{2} \mathrm{IrO}_{3}$. Nat. Mater. 2017, $16,(5), 580-586$.

21. Seo, D. H.; Lee, J.; Urban, A.; Malik, R.; Kang, S.; Ceder, G., The structural and chemical origin of the oxygen redox activity in layered and cation-disordered Li-excess cathode materials. Nat. Chem. 2016, 8, (7), 692-7.

22. Saubanère, M.; McCalla, E.; Tarascon, J. M.; Doublet, M. L., The intriguing question of anionic redox in high-energy density cathodes for Li-ion batteries. Energy Environ. Sci. 2016, 9, (3), 984-991.

23. Gent, W. E.; Lim, K.; Liang, Y.; Li, Q.; Barnes, T.; Ahn, S. J.; Stone, K. H.; McIntire, M.; Hong, J.; Song, J. H.; Li, Y.; Mehta, A.; Ermon, S.; Tyliszczak, T.; Kilcoyne, D.; Vine, D.; Park, J. H.; Doo, S. K.; Toney, M. F.; Yang, W.; Prendergast, D.; Chueh, W. C., Coupling between oxygen redox and cation migration explains unusual electrochemistry in lithium-rich layered oxides. Nat. Commun. 2017, 8, (1), 2091.

24. Hong, J.; Gent, W. E.; Xiao, P.; Lim, K.; Seo, D. H.; Wu, J.; Csernica, P. M.; Takacs, C. J.; Nordlund, D.; Sun, C. J.; Stone, K. H.; Passarello, D.; Yang, W.; Prendergast, D.; Ceder, G.; 
Toney, M. F.; Chueh, W. C., Metal-oxygen decoordination stabilizes anion redox in Li-rich oxides. Nat. Mater. 2019, 18, (3), 256-265.

25. Xie, Y.; Saubanère, M.; Doublet, M. L., Requirements for reversible extra-capacity in Lirich layered oxides for Li-ion batteries. Energy Environ. Sci. 2017, 10, (1), 266-274.

26. Ben Yahia, M.; Vergnet, J.; Saubanère, M.; Doublet, M.-L., Unified picture of anionic redox in Li/Na-ion batteries. Nat. Mater. 2019, 18, (5), 496-502.

27. Xu, J.; Sun, M.; Qiao, R.; Renfrew, S. E.; Ma, L.; Wu, T.; Hwang, S.; Nordlund, D.; Su, D.; Amine, K.; Lu, J.; McCloskey, B. D.; Yang, W.; Tong, W., Elucidating anionic oxygen activity in lithium-rich layered oxides. Nat. Commun. 2018, 9, (1), 947.

28. Yang, W.; Devereaux, T. P., Anionic and cationic redox and interfaces in batteries: Advances from soft X-ray absorption spectroscopy to resonant inelastic scattering. J. Power Sources 2018, 389, 188-197.

29. Qiao, R.; Chuang, Y. D.; Yan, S.; Yang, W., Soft x-ray irradiation effects of $\mathrm{Li}_{2} \mathrm{O}_{2}$, $\mathrm{Li}_{2} \mathrm{CO}_{3}$ and $\mathrm{Li}_{2} \mathrm{O}$ revealed by absorption spectroscopy. PloS one 2012, 7, (11), e49182.

30. Cao, G.; Qi, T. F.; Li, L.; Terzic, J.; Yuan, S. J.; DeLong, L. E.; Murthy, G.; Kaul, R. K., Novel Magnetism of $\operatorname{Ir}^{5+}\left(5 \mathrm{~d}^{4}\right)$ Ions in the Double Perovskite $\mathrm{Sr}_{2} \mathrm{YIrO}_{6}$. Phys. Rev. Lett. 2014, 112, (5), 056402.

31. Terzic, J.; Zheng, H.; Ye, F.; Zhao, H. D.; Schlottmann, P.; De Long, L. E.; Yuan, S. J.; Cao, G., Evidence for a low-temperature magnetic ground state in double-perovskite iridates with $\operatorname{Ir}^{5+}\left(5 \mathrm{~d}^{4}\right)$ ions. Phys. Rev. B 2017, 96, (6), 064436.

32. Shadle, S. E.; Hedman, B.; Hodgson, K. O.; Solomon, E. I., Ligand K-Edge X-ray Absorption Spectroscopy as a Probe of Ligand-Metal Bonding: Charge Donation and Covalency in Copper-Chloride Systems. Inorg. Chem. 1994, 33, (19), 4235-4244. 
33. Solomon, E. I.; Hedman, B.; Hodgson, K. O.; Dey, A.; Szilagyi, R. K., Ligand K-edge Xray absorption spectroscopy: covalency of ligand-metal bonds. Coord. Chem. Rev. 2005, 249, (1), 97-129.

34. Oishi, M.; Fujimoto, T.; Takanashi, Y.; Orikasa, Y.; Kawamura, A.; Ina, T.; Yamashige, H.; Takamatsu, D.; Sato, K.; Murayama, H.; Tanida, H.; Arai, H.; Ishii, H.; Yogi, C.; Watanabe, I.; Ohta, T.; Mineshige, A.; Uchimoto, Y.; Ogumi, Z., Charge compensation mechanisms in $\mathrm{Li}_{1.16} \mathrm{Ni}_{0.15} \mathrm{Co}_{0.19} \mathrm{Mn}_{0.50} \mathrm{O}_{2}$ positive electrode material for Li-ion batteries analyzed by a combination of hard and soft X-ray absorption near edge structure. J. Power Sources 2013, 222, $45-51$.

35. Yabuuchi, N.; Takeuchi, M.; Nakayama, M.; Shiiba, H.; Ogawa, M.; Nakayama, K.; Ohta, T.; Endo, D.; Ozaki, T.; Inamasu, T.; Sato, K.; Komaba, S., High-capacity electrode materials for rechargeable lithium batteries: $\mathrm{Li}_{3} \mathrm{NbO}_{4}$-based system with cation-disordered rocksalt structure. Proc. Natl. Acad. Sci. 2015, 112, (25), 7650-7655.

36. Li, H.; Ramakrishnan, S.; Freeland, J. W.; McCloskey, B. D.; Cabana, J., $\mathrm{Li}_{3} \mathrm{RuO}_{4}$ Polymorphs. J. Am. Chem. Soc. 2020, 142, (18), 8160-8173.

37. Hu, E.; Yu, X.; Lin, R.; Bi, X.; Lu, J.; Bak, S.; Nam, K.-W.; Xin, H. L.; Jaye, C.; Fischer, D. A.; Amine, K.; Yang, X.-Q., Evolution of redox couples in Li- and Mn-rich cathode materials and mitigation of voltage fade by reducing oxygen release. Nat. Energy 2018, 3, (8), 690-698.

38. Lebens-Higgins, Z. W.; Vinckeviciute, J.; Wu, J.; Faenza, N. V.; Li, Y.; Sallis, S.; Pereira, N.; Meng, Y. S.; Amatucci, G. G.; Der Ven, A. V.; Yang, W.; Piper, L. F. J., Distinction between Intrinsic and X-ray-Induced Oxidized Oxygen States in Li-Rich 3d Layered Oxides and $\mathrm{LiAlO}_{2}$. J. Phys. Chem. C 2019, 123, (21), 13201-13207.

39. House, R. A.; Maitra, U.; Pérez-Osorio, M. A.; Lozano, J. G.; Jin, L.; Somerville, J. W.; 
Duda, L. C.; Nag, A.; Walters, A.; Zhou, K.-J.; Roberts, M. R.; Bruce, P. G., Superstructure control of first-cycle voltage hysteresis in oxygen-redox cathodes. Nature 2020, 577, (7791), $502-508$.

40. House, R. A.; Rees, G. J.; Pérez-Osorio, M. A.; Marie, J.-J.; Boivin, E.; Robertson, A. W.; Nag, A.; Garcia-Fernandez, M.; Zhou, K.-J.; Bruce, P. G., First-cycle voltage hysteresis in Lirich 3d cathodes associated with molecular $\mathrm{O}_{2}$ trapped in the bulk. Nat. Energy 2020, 5, (10), 777-785.

41. Li, L.; Castro, F. C.; Park, J. S.; Li, H.; Lee, E.; Boyko, T.; Freeland, J. W.; Yao, Z.; Fister, T. T.; Vinson, J.; Shirley, E. L.; Wolverton, C.; Cabana, J.; Dravid, V. P.; Thackeray, M. M.; Chan, M. K. Y., Probing Electrochemically-Induced Structural Evolution and Oxygen Redox Reactions in Layered Lithium Iridate. Chem. Mater. 2019, 31. (12), 4341- 4352.

42. Gent, W. E.; Abate, I. I.; Yang, W.; Nazar, L. F.; Chueh, W. C., Design Rules for HighValent Redox in Intercalation Electrodes. Joule 2020, 4, (7), 1369-1397.

43. Lebens-Higgins, Z. W.; Faenza, N. V.; Radin, M. D.; Liu, H.; Sallis, S.; Rana, J.; Vinckeviciute, J.; Reeves, P. J.; Zuba, M. J.; Badway, F.; Pereira, N.; Chapman, K. W.; Lee, T.L.; Wu, T.; Grey, C. P.; Melot, B. C.; Van Der Ven, A.; Amatucci, G. G.; Yang, W.; Piper, L. F. J., Revisiting the charge compensation mechanisms in $\mathrm{LiNi}_{0.8} \mathrm{Co}_{0.2-\mathrm{y}} \mathrm{Al}_{\mathrm{y}} \mathrm{O}_{2}$ systems. Mater. Horiz. 2019, 6, (10), 2112-2123.

44. Li, N.; Sallis, S.; Papp, J. K.; Wei, J.; McCloskey, B. D.; Yang, W.; Tong, W., Unraveling the Cationic and Anionic Redox Reactions in a Conventional Layered Oxide Cathode. ACS Energy Lett. 2019, 4, (12), 2836-2842.

45. Sathiya, M.; Rousse, G.; Ramesha, K.; Laisa, C. P.; Vezin, H.; Sougrati, M. T.; Doublet, M. L.; Foix, D.; Gonbeau, D.; Walker, W.; Prakash, A. S.; Ben Hassine, M.; Dupont, L.; 
Tarascon, J. M., Reversible anionic redox chemistry in high-capacity layered-oxide electrodes. Nat. Mater. 2013, 12, (9), 827-35.

46. Sathiya, M.; Abakumov, A. M.; Foix, D.; Rousse, G.; Ramesha, K.; Saubanere, M.; Doublet, M. L.; Vezin, H.; Laisa, C. P.; Prakash, A. S.; Gonbeau, D.; VanTendeloo, G.; Tarascon, J. M., Origin of voltage decay in high-capacity layered oxide electrodes. Nat. Mater. 2015, 14, (2), 230-8.

47. Rana, J.; Papp, J. K.; Lebens-Higgins, Z.; Zuba, M.; Kaufman, L. A.; Goel, A.; Schmuch, R.; Winter, M.; Whittingham, M. S.; Yang, W.; McCloskey, B. D.; Piper, L. F. J., Quantifying the Capacity Contributions during Activation of $\mathrm{Li}_{2} \mathrm{MnO}_{3}$. ACS Energy Lett. 2020, 5, (2), 634641.

48. Jacquet, Q.; Iadecola, A.; Saubanère, M.; Lemarquis, L.; Berg, E. J.; Alves Dalla Corte, D.; Rousse, G.; Doublet, M.-L.; Tarascon, J.-M., Competition between Metal Dissolution and Gas Release in Li-Rich $\mathrm{Li}_{3} \mathrm{Ru}_{\mathrm{y}} \mathrm{Ir}_{1-\mathrm{y}} \mathrm{O}_{4}$ Model Compounds Showing Anionic Redox. Chem. Mater. 2018, 30, (21), 7682-7690.

49. Kobayashi, H.; Tabuchi, M.; Shikano, M.; Kageyama, H.; Kanno, R., Structure, and magnetic and electrochemical properties of layered oxides, $\mathrm{Li}_{2} \mathrm{IrO}_{3}$. J. Mater. Chem. 2003, 13, (4), 957-962. 


\section{TOC graphic}

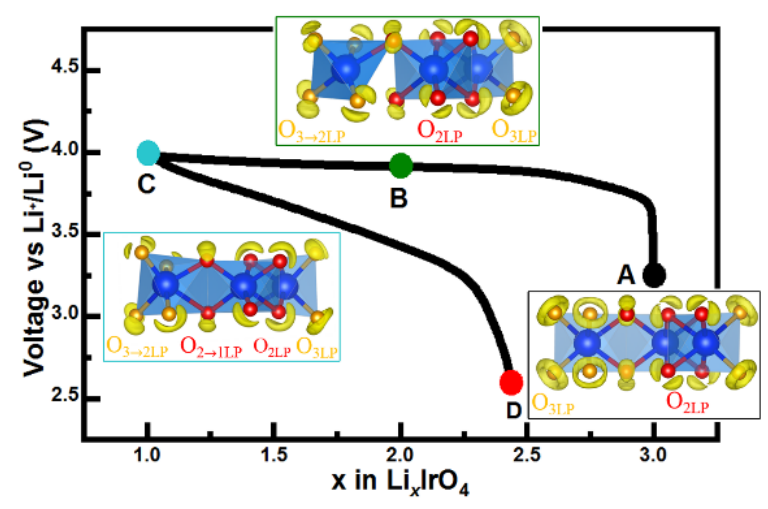

